\title{
QCM as Cell-Based Biosensor
}

\author{
Tsong-Rong Yan, Chao-Fa Lee and Hung-Che Chou \\ Institute of Bioengineering, Tatung University \\ Taiwan, R.O.C.
}

\section{Introduction}

\subsection{History of the quartz crystal microbalance}

Piezoelectricity is defined as electric polarization produced by mechanical strain in certain crystals, the polarization being proportional to the strain (Cady, 1946). The Curies first observed piezoelectricity in 1880 as a potential difference generated across two surfaces of a quartz crystal under strain. The converse piezoelectric effect, the deformation of a piezoelectric material by an applied electric field, was predicted by Lippmann (Lippmann, 1881). In 1959 Sauerbrey provided a description and experimental proof of the massfrequency relation for foreign layers deposited on thickness-shear mode crystals that are still widely used today for determination of mass-sensing format is commonly referred to as the QCM. The mass increases when a film is deposited onto the crystal surface and monolayer sensitivity is easily reached (Lu \& Lewis, 1972). However, when the film thickness increases, viscoelastic effects come into play. In the late 80's, it was recognized that the QCM can also be operated in liquids (Konash \& Bastiaans, 1980), if proper measures are taken to overcome the consequences of the large damping and viscoelastic effects contribute strongly to the resonance properties (Bruckenstein \& Shay, 1985; Ward \& Buttery, 1990). Today, microweighing is one of several uses of the QCM (Johannsmann, 2008). Measurements of viscosity and more general, viscoelastic properties, are of much importance as well. The "non-gravimetric" QCM is by no means an alternative to the conventional QCM. Many researchers, who use quartz resonators for purposes other than gravimetry, have continued to call the quartz crystal resonator "QCM". Actually, the term "balance" makes sense even for non-gravimetric applications if it is understood in the sense of a force balance. At resonance, the force exerted upon the crystal by the sample is balanced by a force originating from the shear gradient inside the crystal. This is the essence of the small-load approximation.

\subsection{Biological applications of the QCM}

The use of biological coatings, such as enzymes and antibodies, was a natural progression from the initial piezoelectric $(\mathrm{Pz})$ sensor development. The first reported gas phase biosensor was in fact an enzyme-based $\mathrm{Pz}$ sensor (Guilbault, 1983). The first $\mathrm{Pz}$ immunosensor for microbial pathogens was developed by Muramatsu et al. in 1986 (Muramatsu et al., 1986). Their $\mathrm{Pz}$ crystals were coated with antibodies against Candida albicans. The antigen was detected from $1 \times 10^{6}$ to $5 \times 10^{8}$ cells $\mathrm{mL}^{-1}$. The sensor proved to be 
specific with no detectable response observed with the other species tested. Conventional bacterial detection methods generally require laborious procedures and many hours or even days for complete analysis. The relatively large mass of bacterial cells, combined with the availability of antibodies to most species means that $\mathrm{Pz}$ immunosensor detection offers a very attractive alternative to microbiological methods. Generally giving results in minutes, with adequate sensitivity and selectivity. Su \& Li design the automatic QCM immunosensor system was fabricated by immobilizing anti-Salmonella polyclonal antibodies on $8 \mathrm{MHz}$ ATcut quartz crystal with Protein A method. The oscillation frequency of the QCM sensor was monitored in real time ( $\mathrm{Su} \& \mathrm{Li}, 2004)$. The direct detection of nucleic acid interactions based on the use of acoustic wave devices was first provided by Fawcett et al. (Fawcett et al., 1988). They described a quartz crystal microbalance (QCM)-based biosensor for DNA detection by immobilizing single-stranded DNA onto quartz crystals and detecting the mass changes after hybridization. Since this early work, a number of articles have appeared employing similar procedures, resulting in microgravimetric measurements based on nucleic acids (Itamar et al., 2002). A QCM detection system consisted of a sensitive element (QCM wafer), an inlet subsystem, and a frequency acquisition unit. In Hao et al. work, a DNA probe functionalized quartz crystal microbalance (QCM) biosensor was developed to detect $B$. anthracis based on the recognition of its specific DNA sequences (Hao et al., 2011).

\subsection{The QCM in cell biological}

The QCM was already well-known and established as an analytical tool for studying adsorption phenomena at the solid-liquid interface (Martin et al., 1991; Buttry \& Ward, 1992) when its potential for studying cell-substrate adhesion was recognized. It was then recognized that the adhesion of cells to the quartz surface also induced a shift in resonance frequency that was shown to be linearly correlated with the fractional surface coverage (Gryte et al., 1993; Redepenning et al., 1993). Time-resolved measurements of the resonance frequency were then used to follow the attachment and spreading of cells to the quartz surface, with extraordinary time resolution. Comparison with established cytological techniques has proven that the QCM readout reports reliably on the number of cells on the surface and the time course of adhesion (Wegener et al., 1998). Specifically, they have demonstrated that QCM is a convenient method for measuring in real time the attachment of African Green Monkey kidney cells as well as their detachment that accompanies cell death caused by either $\mathrm{NaOH}$ addition or virus infection. Additionally, the observed QCM responses are consistent with attached cell layers that behave as viscous films rather than rigid masses, illustrating that care must be exercised in the interpretation of QCM measurements involving cell adhesion or binding events.

Impedance analysis of cell-covered gold-film electrodes was first introduced by Giaever and Keese (Giaever \& Keese, 1991, 1993), who showed that the frequency dependent electrical impedance for such a system is dependent on the impedance of the cell-free electrode, the resistance between adjacent cells, $\mathrm{Rb}$, the capacitance of the cell membranes, $\mathrm{Cm}$, and an additional impedance contribution that is associated with the current flow between the basal plasma membrane and the substrate. The resistance, $\mathrm{Rb}$, is dependent on the width of the intercellular cleft between adjacent cells and the establishment of tight junctions, and is therefore a sensitive parameter for cell-cell contacts. Thus, impedance analysis of the shear displacement (from now on referred to as "quartz mode") and impedance analysis of the cell-covered surface electrode (referred to as "cell mode") may provide independent 
information about the establishment of cell-substrate and cell-cell contacts. A computercontrolled relay allows switching between both modes.

Pioneering works using the QCM showed that viscoelastic properties of films deposited on the sensor surface can be examined using frequency changes (Kanazawa \& Gordon, 1985; Okahata et al., 1989). However, measurement of alone is not easily and specifically related to structural or conformational changes occurring at the sensor surface, especially for cytoskeletal changes that imply cellular volume and mass redistribution over the adhesion surface. Additionally, the energy dissipation needs to be monitored to detect cytoskeletal changes because cell responses can be interpreted (or modeled) as a purely liquid effect as well as a purely elastic mass effect (Marx et al., 2003). Most real scenarios are actually in between these two limits. Rodahl et al. extended the QCM technique by performing the direct monitoring of energy dissipation (D) considered a useful indicator of the viscoelastic properties of the material deposited at the sensor surface (Rodahl et al., 1996a, 1996b). Among the different QCM-D investigations of cells, it was showed that the interaction between cells and a surface produced a unique and reproducible dissipation against frequency plot, also referred to as a QCM-D signature (Fredriksson, 1998a, 1998b).

These new tools were called as the whole-cell QCM biosensor. Initial use of the QCM was for measuring chemicals in the gas phase binding the QCM surface and more recently as a tool in analytical electrochemistry.

In the past decades the QCM has been used to create biosensors. Infrequently, whole cells have been studied at the QCM surface (Gryte et al., 1993; Muratsugu et al., 1997; Wegener et al., 1998). Marx suggests the potential of this cellular biosensor for the real-time identification or screening of all classes of biologically active drugs or biological macromolecules that affect cellular attachment and cellular spreading, regardless of their molecular mechanism of action (Marx et al., 2003, 2007). The interconnected cytoskeleton structural elements depicted provide targets for drugs or macromolecules that bind and alter their structures or dynamical properties. Biosensor output is proportional to a particular detected concentration of the drug or macromolecule effector.

\subsection{Scope of the present study}

Applications for the QCM have been invested in our laboratory for a long-term. We combine some surface modify methods to immobilize the oligonucleotide probe on the gold electrode surface of QCM that could use to detect the PCR product of Vibrio parahaemolyticus and breast cancer. We study a modified antibody-coated QCM biosensor will be constructed for detecting food pathogenic bacteria Vibrio parahaemolyticus and to find the most suitable surface modification method. We have recently started to observe and research the cell growth process on QCM. Utilize a silver electrode QCM mass sensor to detect the physiology of cells by the plasma surface modification as a protection film (Chou et al., 2009). Develop a new method that utilizes the QCM technique to measure the tight junction of the Caco-2 cell (Chou \& Yan, 2010). Using QCM to design a cell detection platform is an important application of QCM. In the process of system design and application, there still have some points, which are easily overlooked or are not understood by researchers. Most of the problems can be separated into three types. One is the cell culture environment conditions that affect the system signals, another is the 
system unification or lack of communication over regulations, and the other is the overanalysis of the experimental data (Chou et al., 2009). A QCM has been constructed and used for chemical sensing and biochemical detecting. Frequency shift has a relation with mass changed in the gaseous condition. However, the velocity, density, and viscosity also cause frequency changed in liquid solution. We develop a new method and system to investigate the variable value of amplitude and frequency from the oscillator of quartz (Lee et al., 2009). A biosensor consists of the immobilized biological recognition element (e.g. antibody, DNA, enzyme, receptor, microorganism, or cell) in intimate contact with a signal transducer (electrochemical, optical, thermal, or acoustic signal) that together permit analysis of chemical properties or quantities. We show that the QCM technique is a sensitive method not only to measure quasi-static cell adhesion processes but also dynamic changes of mechanical cell properties. A new cell-based QCM biosensor system which can real-time monitor the adhesion and growth of animal cells will be developed. A QCM chip sensor can measure the frequency, amplitude, trans-epithelial resistance, and A/C impedance. These materials were all fabricated under the cell unit to monitor cell growth conditions (Lee et al., 2010).

\section{Electronic behavior of quartz resonators}

QCM (Quartz crystal microbalance) refers to a sensor based on a piezo-electric. A QCM can be used in fixed and immobility area, and the mass can be found while changing the surface of the QCM with the relation between mass and frequency in Sauerbrey formula (Sauerbrey, 1959). The change of frequency $(\Delta f)$ is proportional to the added mass $(\Delta M)$ Eq. (1). The characteristic can merely be adapted to special application. QCM can be used as gas detectors when coated with various materials (King, 1964).

$$
\Delta f=\frac{2 f_{0}^{2}}{\sqrt{\mu_{q} \rho_{q}}} \frac{\Delta M}{A}
$$

$f_{0}, \mu_{q}, \rho_{q}$, and A denote the specific resonant frequency, density, shear modulus and the piezoelectrically active area of quartz, respectively.

The use of biological coatings, such as enzymes and antibodies, was a natural progression from the initial QCM development. Guilbault reported an enzyme-based QCM sensor in gas phase (Guilbault, 1983). A quartz immunosensor for microbial pathogens was developed by Muramatsu et al. (Muramatsu et al., 1986). Since then, liquid QCM began to be applied to cell biology, biotechnology, immunology and electrochemistry. Kanazawaand and Gordan prospected that $\Delta f$ as a linear function of a square root of $\rho_{\mathrm{q}} \times \eta_{\mathrm{q}}$ and $\rho_{\mathrm{w}} \times \eta_{\mathrm{w}}$ (density, $\rho$ and viscosity, $\eta$ ), as shown in Eq. (2) (Kanazawa \& Gordon, 1985). It was discovered that changes in the physical-chemical property of the contacting materials/media will result in frequency changes of the quartz crystal resonator when used in liquid phase (Muramatsu et al., 1988; Shumacher, 1990).

$$
\Delta f_{w} \propto \sqrt{\rho_{\mathrm{q}} \times \eta_{\mathrm{q}}}-\sqrt{\rho_{\mathrm{w}} \times \eta_{\mathrm{w}}}
$$

$\rho_{\mathrm{w}}, \eta_{\mathrm{w}}$ represent the change of dissolvent in liquid phase. 
However, these sealed apparatuses open up the surface functional analysis. A kind of variability situation involves in a liquid media, there are some and important significant phenomena due to liquid contact. For the quartz crystal in contact with liquid, the resonant resistance change was first derived by Muramatsu et al., as shown in Eq. (3).

$$
\Delta \mathrm{R}=\left(2 \pi 2 \rho_{1} \eta\right)^{1 / 2} \mathrm{~A} / \mathrm{k}^{2}
$$

where $\mathrm{k}$ is the electromechanical coupling factor.

References are also made to other types of electrochemical detection techniques, such as impedance analysis that measures both resistance and reactance (Mirsky et al., 1997). The oscillation was damped and the Q factor was significantly reduced (Auge et al., 1994). Q factor formula can be described in liquid applications as shown in Eq. (4).

$$
Q \approx \frac{\pi \rho_{q} v_{q}^{2}}{\sqrt{2 \omega \rho_{w} \eta_{w}}}
$$

where $v_{q}$ is the velocity of the liquid at the surface and $\omega$ is the angular frequency.

Impedance analysis of cell-covered gold-film electrodes and the frequency dependent electrical impedance for such a system is dependent on the impedance associated with the current flow between the basal plasma membrane and the substrate (Giaever \& Keese, 1991, 1993). More information about changes in dissipation (D) can be obtained via either impedance spectroscopy by recording the oscillation decay or the freely oscillating crystal after rapid excitation at resonance (Rodahl et al., 1995), the $f=f_{0}-f_{r}$ and $D$ are obtained directly via the relation as shown in Eq. (5):

$$
D=\frac{1}{\pi f t}
$$

where $f_{0}$ is the resonance frequency of the crystal, and $f_{r}$ is a constant reference frequency.

Another variety of the reaction from electrochemical and quartz crystal microbalance measurement provides a powerful utility in studying solution phase transformations (Bard $\&$ Faulkner, 2001). When solution phase reactions are considered, there is also a capacitive component of the current that decays exponentially in time according to the following equation, as shown in Eq. (6).

$$
I_{c}(t)=\frac{\Delta E}{R} e^{-t / R C}
$$

where $\mathrm{R}$ is resistance (ohms) and $\mathrm{C}$ is the capacitance $(\mathrm{F})$.

The above mentioned equation is useful for analysis on QCM sensor. In situ localizes a nonrigid coating, the damping behavior of the crystal is also required and can be evaluated by QCM-D (Edvardsson et al., 2006), electrical impedance (Wudy et al., 2008) and transepithelial resistance (TEER). To establish QCM cell-culture instrument, it is a useful method to monitor the interactions between the cells with the surface of a non-invasive type. The attitude about the entire cells investigated with the process of spreading, separation, movement or ingestion (Tan et al., 2008). 


\section{A construction of QCM measurement}

\subsection{Overview of the system Integration}

A quartz crystal microbalance cell-culture incubator system includes environmental control system, QCM detecting system and data collection system. An environmental control system is divided into two major parts, incubator and cell-container. A QCM detecting system is a real-time measurement of the shift in resonance frequency and energy dissipation due to changes in mass and viscoelastic properties. A trans-epithelial resistance is also monitored in this system. This system was designed two channels of QCM to monitor the grow cell. Use 8-bits processor (Pic18F45J10, Microchip) and a complex programmable logic device (CPLD, LCMXO640, Lattice) to construct measurement and control circuit. All signal materials can make a hand-shaking, recording and controlled via computer synchronically (Fig. 1).

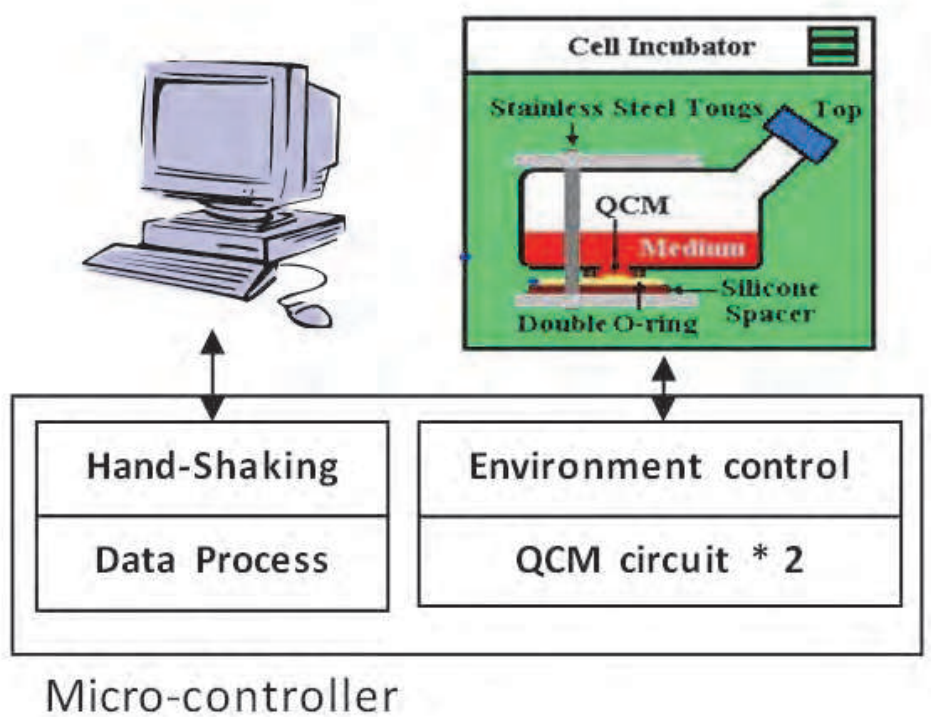

Fig. 1. Schematic diagram of the proposed QCM cell detection system.

Cells can be isolated from tissues for ex vivo culture in several ways. Mononuclear cells can be released from soft tissues by enzymatic digestion with enzymes such as collagenase, trypsin, or pronase, which break down the extracellular matrix. Alternatively, pieces of tissue can be placed in growth media, and the cells that grow out are available for culture. There are numerous well established cell lines representative of particular cell types. Fig. 2A shows the schematic system design of this study. The system includes three parts: the cell incubator chamber, the QCM sensor chip, and the circuit system. Signals are detected by a sensor chip, stored on a personal computer (PC), and are processed by custom made software. The cell incubator chamber is made of Pyrex1 glass, together with stainless steel tongs and other accessories to sterilize the autoclave directly. The QCM biosensor used in this study was purchased from a local source (Mercury Electronics Ind. Co., Ltd., Taiwan) and only the bare crystal was fixed on a ceramic base. 
Fig. 2B shows that the QCM is inlaid on the ceramic substrate so that the twist force does not directly contact the chip surface. This design stabilizes the chip effectively during oscillation when the chip is connected to the incubator chamber. The gold electrode connected to the chip is behind the ceramic substrate to avoid any biotoxicity caused by line materials in the connect circuit contacting the cell culture solution. By having the ceramic substrate on the double o ring, it not only prevents solution leakage from the cell incubator chamber, but also reduces the possibility of contamination. All chip materials that contact the cells have improved biocompatibility so they do not influence the growth of cells. A Glass tank used to culture the cell and has a detection portion in the underside. Glass tank is made of Pyrex ${ }^{\circledR}$ glass and chip material choice has a good biocompatibility. All materials do not affect cell growth.
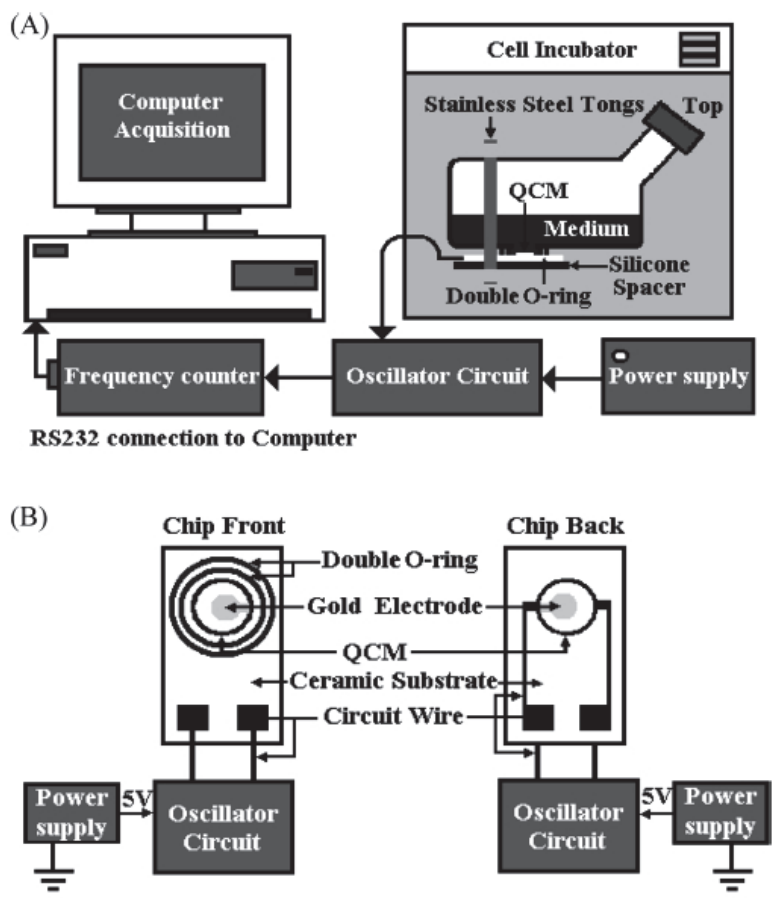

Fig. 2. Schematic diagram of the proposed QCM cell detection system. (A) Schematic diagram of the measurement system hardware setup used the QCM; (B) Schematic diagram of the QCM sensor chip.

\subsection{Circuit description}

\subsubsection{Self-resonant circuit and amplitude capture}

A Pierce oscillator uses an inverting amplifier so that its phase of $180^{\circ}$ must be shifted to $360^{\circ}$ through the feedback network, in order to fulfill the phase condition (Pierce, 1923). In our system, self-resonant circuit was designed with a $50 \%$ duty cycle crystal oscillator, based 
on the Pierce oscillator. A peak-detector can be applied as a sample and to be held as the amplitude of oscillator. We used two op-amps to amplify the differential input signals and a diode to hold the peak of amplitude. Fig. 3. Shows the circuit using two comparators (AD8564, Analog Devices) and one op-amp (MC33204, On Semiconductor). We designed a $50 \%$ duty cycle crystal oscillator. One comparator produces the resonance with quartz. The other just generates a reverse clock. The AD8564 is a quad 7 ns comparator. The fast $7 \mathrm{~ns}$ propagation delay makes a good choice for timing circuit. The MC33204 is a general operational amplifier. This op-amp offers a balance reference voltage. This circuit can generate an equal width square clock. The output frequency of square clock is up to $10 \mathrm{MHz}$ and be examined in this experiment.

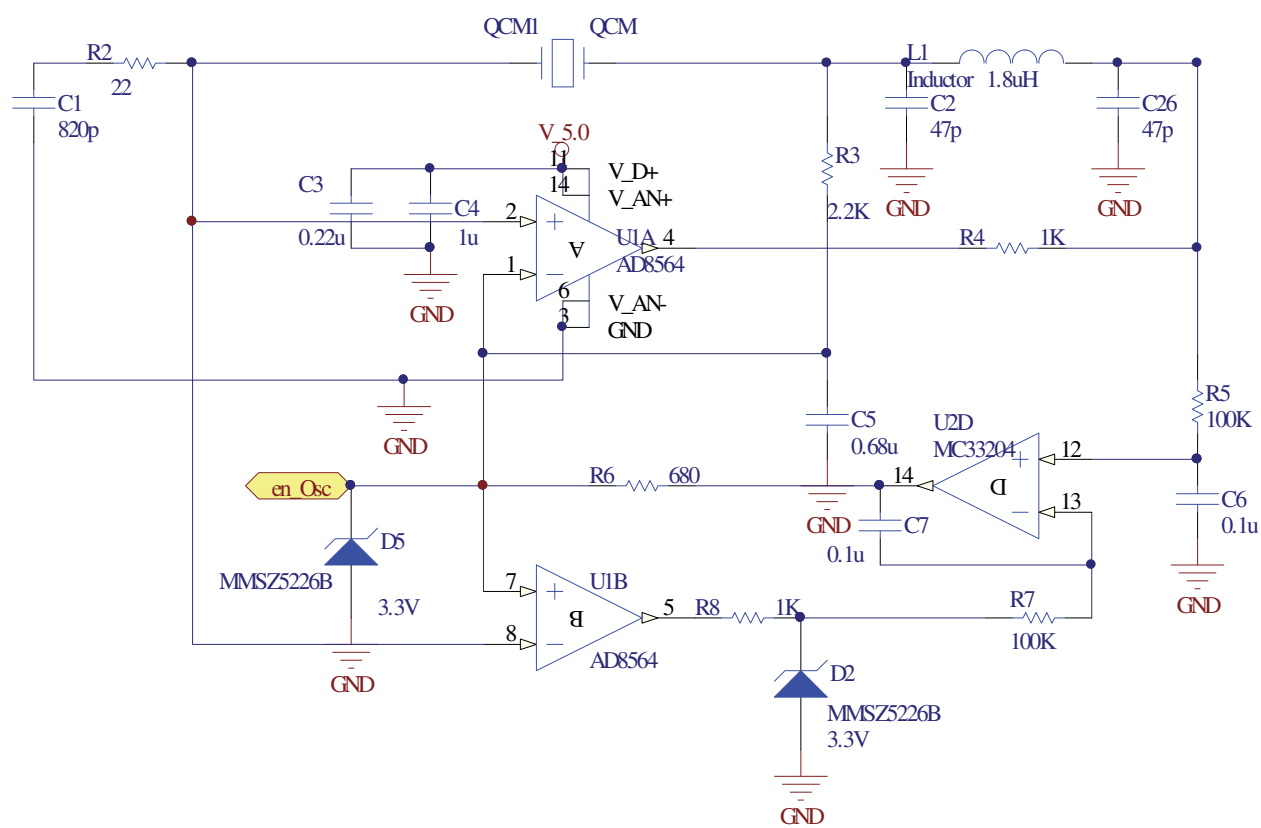

Fig. 3. A 50\% duty cycle crystal oscillator design used two comparators and one op-amp.

\subsubsection{Dual mode measurement system with frequency and impedance analysis}

Accordingly, this topic directed to integrate these measurement materials of frequency, amplitude, and an impedance measurement system into a same measurement system. In an embodiment of this circuit, a voltage control oscillator (VCO) and a signal generator for the frequency scanning were included. The measurement circuit may generate output of the frequency scanning signal through a phase lock loop (PLL). Thus, the QCM system can simultaneously measure these properties of the object on QCM. Simple electrical impedance was described with measuring amplitudes of opposition to alternating current. A frequency generator (4-16 MHz) was built in this system, based on a phase-locked loop (PLL) circuit (TLC2933, TI). The TLC2933 was designed for PLL systems and was composed of a voltage-controlled oscillator (VCO) and an edge-triggered-type phase 
frequency detector. The circuit structure in this embodiment of this topic is further illustrated below in detail. Fig. 4 is a circuit diagram of a measurement system. The detailed circuits of the oscillation circuit (OC), the clock generation circuit (CGC), the enable circuit (EC), the bias circuit (BC), and the sample and hold circuit (SHC) can be obtained. The switch unit (SW) can be implemented as a two-to-one changeover switch or a multiplexer. When the SW switches to the frequency scanning signal (FSS), FSS output by the CGC is transmitted to the quartz (Q) and to be scanned through the SW, so as to scan the $Q$, followed by generating an output of the impedance sensing signal IMS at the other end of the Q. In addition, it should be noted that the clock output signal (COS) was a generated clock of QCM resonant by the OC and the amplitude output signal (AOS) was an amplified signal of IMS by the SHC.

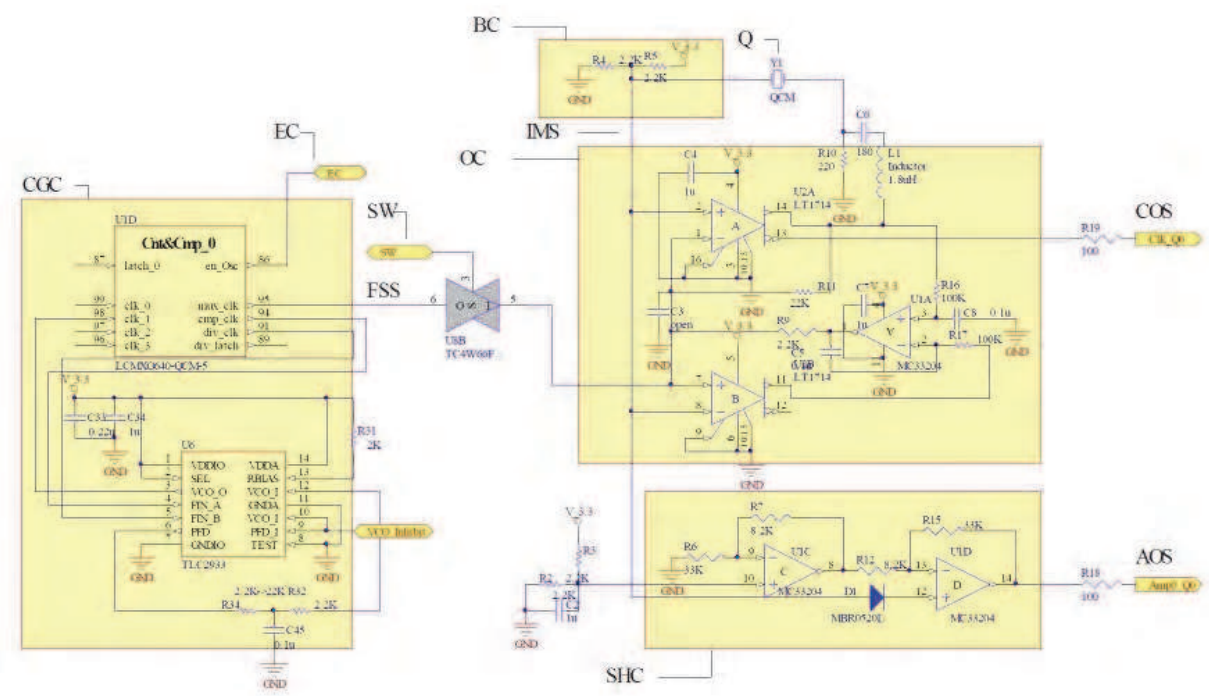

Fig. 4. Dual mode measurement system with frequency and impedance Analysis

\subsubsection{Trans-epithelial resistance circuit}

A cell measurement system, particularly a cell measurement system integrated with a QCM and a technique measuring TEER, is suitable to measure the changes of the frequency and the TEER. Currently, as the techniques are improved, QCMs are gradually used as a sensor in fields such as biological and medical science. Not only are the parameters of QCMs measured, the TEER can also be measured by ion flows between a QCM electrode and an external electrode in our system. A circuit diagram of the cell measurement system is shown in Fig. 5. The cell measurement includes: a power unit (PU), an oscillation module (OM), a frequency-monitoring module (FMM), a level-shift unit (LSU), a quartz crystal sensing module (QSM), a periodic wave-generation module (PWGM), a low-pass filtration module (LPFM), and a control module (CM).The PWGM includes a resistor R1 and a third electrode (E3), and the E3 contacts with a cell lines to be tested as TEER. 


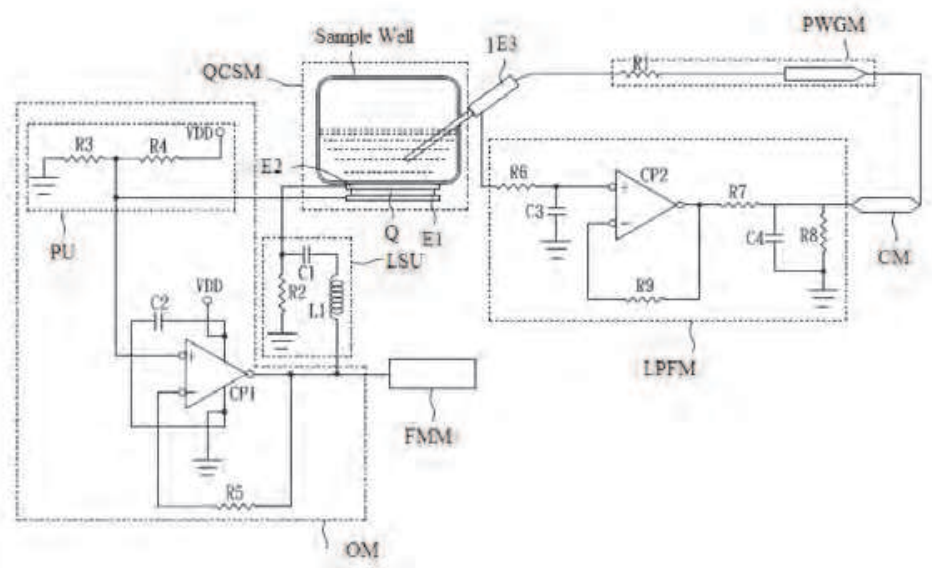

Fig. 5. A circuit of trnas-epithelia electric resistance Measurement

\section{Characters of QCMs from cell monitoring}

Early reports indicated that QCM is based on the absorption of target molecules on the crystal surface causing concomitant change of its resonant frequency (Fawcett et al., 1988). Therefore, QCM can be applied not only to chemical gas adsorption but also to biomolecular detection. When applied to biomolecular reactions, the QCM technique can detect pathogenic bacteria in food (Park \& Kim, 1998) and plant viruses in plant tissue (Eun et al., 2002). Despite the many potential advantages of QCM, relatively few attempts have been made to extend QCM to the measurement of a living cell. For example, researchers have used QCM to examine cell adhesion (Khraiche et al., 2005), apoptosis (Braunhut et al., 2005), and shear-induced senescence (Jenkins et al., 2004) in the past. In addition, the QCM is a versatile and non-invasive in vitro method for real-time characterization of cells.

\subsection{A silver electrode QCM using plasma treatment}

\subsubsection{Reason of using a silver electrode QCM}

The QCM sensors in previous bio-experiments were typically ready-made gold electrode QCMs sold by specific manufacturers. These QCMs are not only expensive, but also lack standards. These is advantages make it hard for researchers to analyze the relationships between cell and chip parameters. However, normal industrial QCMs in the electronics industry market are significantly cheaper and come in more varieties. Moreover, the only difference among QCM chips manufactured by specific manufacturer is that some use a silver material electrode. This change in QCM electrode material causes three major flaws when using silver electrode QCMs in cell detection. First, in the cell culture process, the silver electrode peels off the sensor (Fig. 6A). Second, the general method of helping cells adhere to the electrode by a hydrophilic surface reaction with $\mathrm{H} 2 \mathrm{SO} 4$ or $\mathrm{NH} 3$ solution product does not work with silver QCMs because silver can react with $\mathrm{H} 2 \mathrm{SO} 4$ and NH3, causing the silver electrode to dissolve (Fig. 6B). Third, silver electrode raises potential biotoxicity issues. This study designs a protective film using a plasma-polymerized and photo-induced polymerization reaction process to achieve an optimum design. The 
resulting film not only prevents the silver electrode from peeling but also can wrap silver toxicity in a protective film. Using optimum photo-induced polymerization to increase the hydrophilic level of the surface after plasma-polymerized production film makes it possible to use a silver electrode QCM in cell detection.
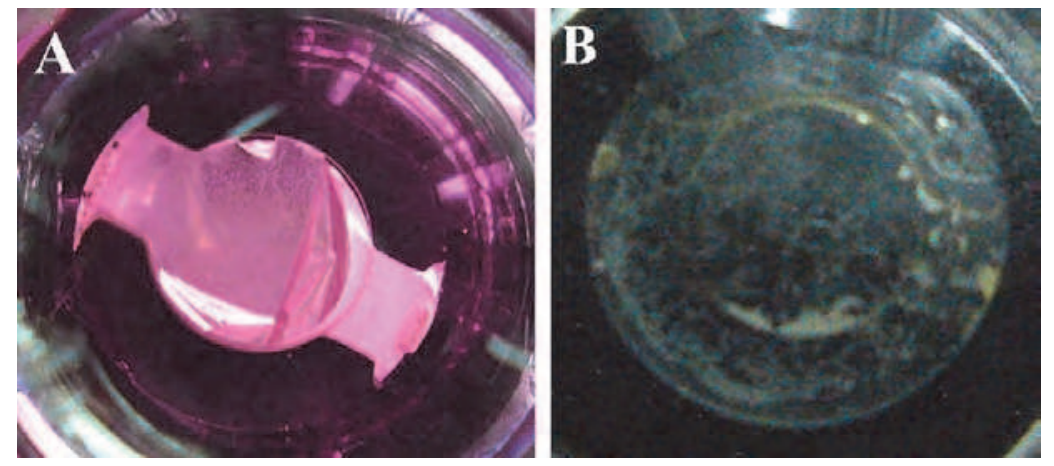

Fig. 6. (A) The silver electrode of the QCM was peeled off by Dulbecco's Modified Eagle's Medium. (B) The silver electrode was dissolved by NH3 solution.

\subsubsection{Preparation of plasma-polymerized film and photo-induced polymerization}

To devise a layer of protective film and solve the problem listed above, selecting a plasmapolymerized film. This is because plasma-polymerized organic layers have many advantageous properties, such as good adhesion to most substrates, excellent uniformity and thickness control, and no pin-hole formation. The elemental composition and physical and chemical properties of organic layers can be varied over a wide range because of their highly branched and cross-linked structures. Due to their biocompatible characteristics, organic films can accept a large amount of biological components, such as cells and tissues that can be loaded onto the surface of the organic layer (Jenkins et al., 2004).

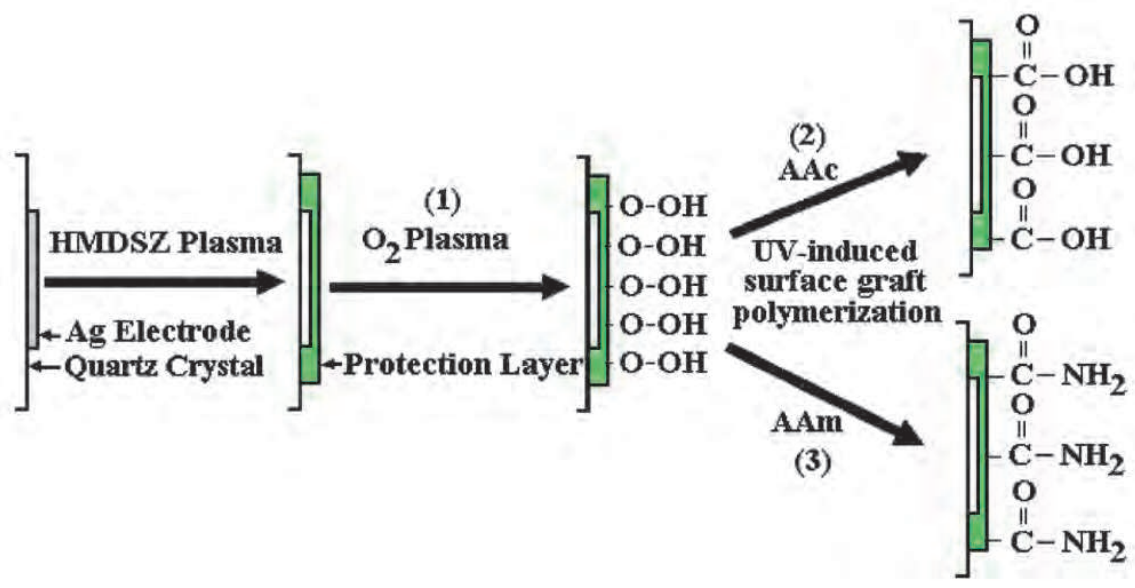

Fig. 7. The scheme of the experiment reaction process. 
Fig. 7 depicts the modification method for binding a protective film and photo-induced polymerization on the QCM. The plasma system used in this study is the same as the one previously shown in (Chen et al., 2007). First, the QCM chip was placed in a RF plasma chamber after cleaning. Silver electrodes on the QCM surface were deposited in organic interlayer films as hexamethyldisilazane (HMDSZ) monomers using the plasma technique. For optimal reaction parameters of deposition, the RF plasma instrument used 100 mTorr of monomer with a plasma power of $30 \mathrm{~W}$. This study tested the change on the QCM chip surface, using HMDSZ reaction times of 1, 3, 5, 7, and $10 \mathrm{~min}$ to form a protective film. After plasma deposition, the silver electrode QCM surface was made hydrophilic by oxygen plasma photo-induced polymerization using the traditional process (Chen et al., 2007; Elsom et al., 2008). This study presents three methods to increase surface hydrophilicity. The first method uses oxygen plasma 40 mTorr oxygen with a power of 100 Wand time of 1 min. After oxygen plasma deposition, two other types of hydrophilic surface methods were designed using surface-grafted acrylamide (AAm) and acrylic acid (AAc) 10\% solution using $1000 \mathrm{~W}$ of UV light irradiation for $30 \mathrm{~min}$ (Fig. 8). Then AAm and AAc homopolymerwere removed from the grafted film by washing the QCM in distilled water three times and drying it in the air.

\section{PIasma CVD system}

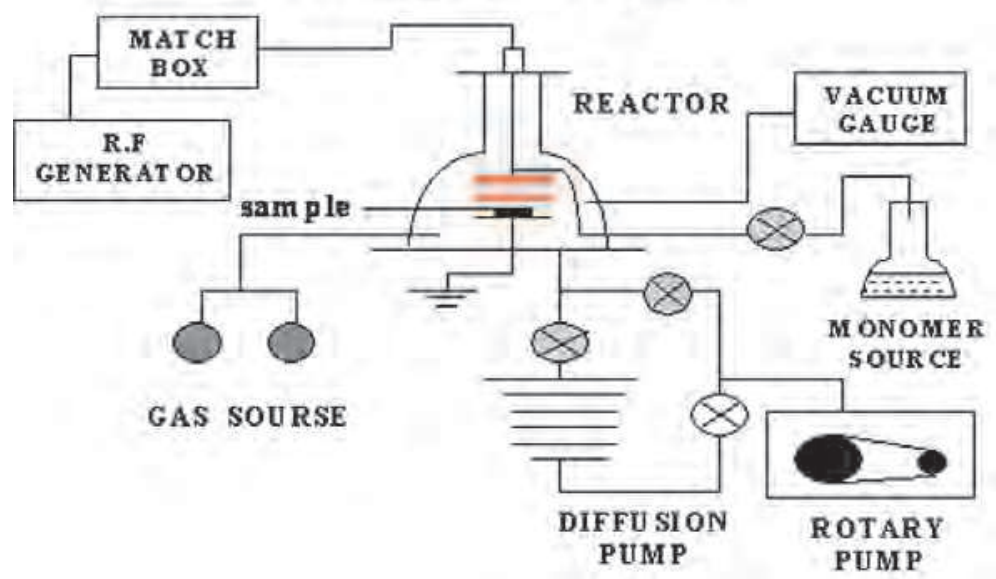

Fig. 8. The plasma treatment system with radio frequency

\subsubsection{Measurement of cell adhesion by cell QCM platform}

The silver QCM surface was first covered with a plasma polymerized film and photoinduced polymerization to render it resistant to solution and hydrophilic. The QCM surface was then cleaned by rinsing with distilled water and air drying. Next, the chip was sterilized by spraying it with ethanol and exposing it to UV light for $30 \mathrm{~min}$. After combining the cell incubator chamber and the QCM sensor (Fig. 9), 500 ul medium was added to the incubator chamber to complete the connection of chip circuit line and oscillator circuit. When turning on the system, testing cells $1 \times 10^{5}$ were added until the system became stable. After achieving a stable signal, the cell incubator chamber was placed in a cell incubator to process the culture. 


\subsubsection{Results}

Fig. 10 shows the results of applying a silver electrode QCM to cell detection. For untreated silver electrode QCMs, the frequency decreases quickly (Fig. 10A), and becomes worse after seeding the cells (Fig. 10B).The process of falling off decreases the chip's shaking ability, which causes the frequency to drop. Experiments with the HMDSZ protective film and photo-induced polymerization of AAm show that frequency remains steady in silver QCMs without adding cells (Fig. 10A). Adding cells simply caused the cells to grow on the chip surface (Fig. 10B). The frequency declines slowly at first, and then increases as the number of cells increases. After cell growth reaches a steady state, $\Delta \mathrm{f}$ also remains steady. As the medium nutrients run out, the quantity of dead cells increases, which cause the frequency to rise slowly. The same result appears in other papers utilizing gold QCMs (Zhou et al., 2000; Nimeri et al., 1998).

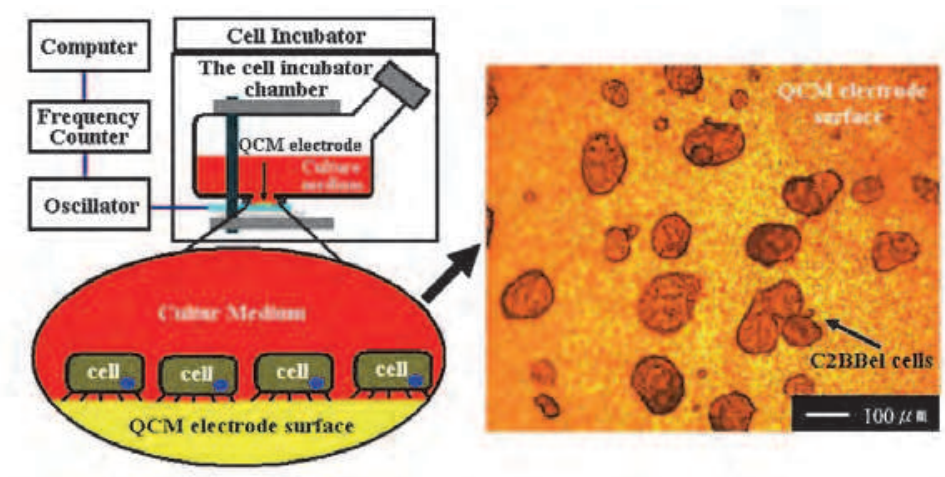

Fig. 9. Schematic diagram of the cell detection system hardware setup used for the QCM, and the condition of C2BBel cells growth on the QCM surface.
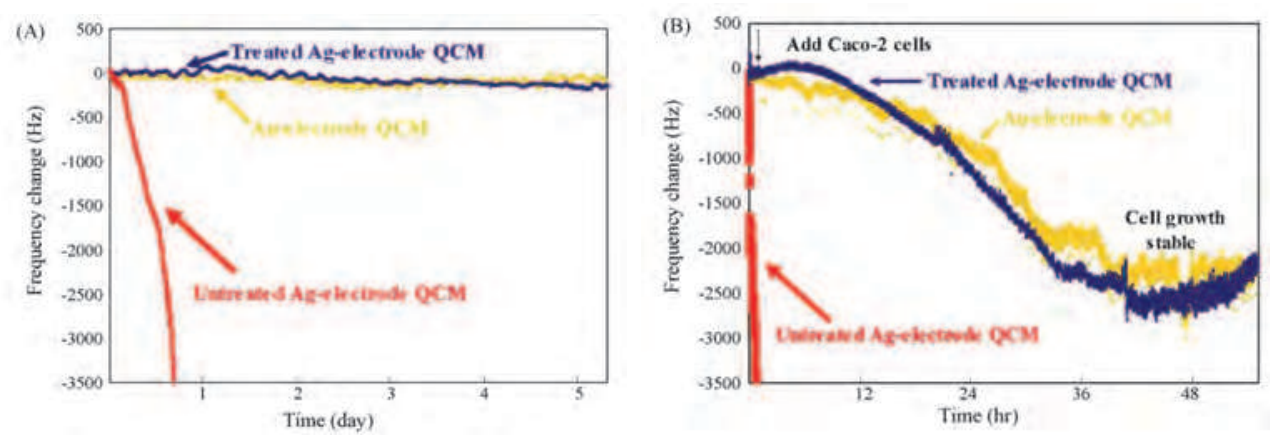

Fig. 10. (A) Frequency change with time of QCM in response to the gold electrode (positive control), the sliver electrode and the treated-sliver electrode QCM. (B) Added $1 \times 10^{6} \mathrm{Caco}-2$ cells on the gold electrode, sliver electrode and the treatment silver electrode QCM surface, respectively. The Au electrode QCM was gold electrode QCM for positive control group with no any others method to treatment, and the treated Ag electrodes were HMDSZ plasma-polymerization times at $10 \mathrm{~min}$, oxygen plasma at $1 \mathrm{~min}$, photo-induced polymerization of AAm. The data points for every $10 \mathrm{~s}$ and made a shift line. 


\subsection{Frequency response of QCM to detect the epithelial cell tight junction}

\subsubsection{QCM frequency characterization}

We selected 9MHz AT-cut QCM (7mm diameter) sensors to be laid on a ceramic substrate. The fractional frequency change caused by the adsorption of the target molecules is estimated by the Sauerbrey (1959) equation that was modified by Jenkins et al. (2004) as shown in Eq. (7):

$$
\frac{\Delta m}{A}=-(\mu \rho)^{0.5} \frac{\Delta f}{2 \pi f_{0}^{2}}
$$

where $\Delta f$ is the change in frequency, $f_{0}$ is the resonance frequency of the crystal $(9 \mathrm{MHz}$ at $\left.25{ }^{\circ} \mathrm{C}\right), \Delta m$ is the change of weight on the quartz crystal surface $(\mathrm{g})$, and $\mathrm{q}$ is the density of quartz $\left(2.648 \mathrm{~g} \mathrm{~cm}^{-3}\right)$. The $\mathrm{m}$ is the shear modulus of quartz $\left(2.947 \times 10^{11} \mathrm{dyn} \mathrm{cm}^{-2}\right)$; $\mathrm{A}$ is the electrode area $\left(9.08 \mathrm{~mm}^{2}\right)$. The aforementioned formula shows that the electrode plays an important role in QCM detection. The QCM detection range is determined by the electrode surface area (Li et al. 2005). Nimeri et al. (1998) also mentioned that the highest and the lowest sensitivities occur at the center and the perimeter of the electrode, respectively. This implies that QCM detection should be focused on the center of the electrode. If the weight of electrode surface is constant, but liquid viscosity-density change in the solution above the

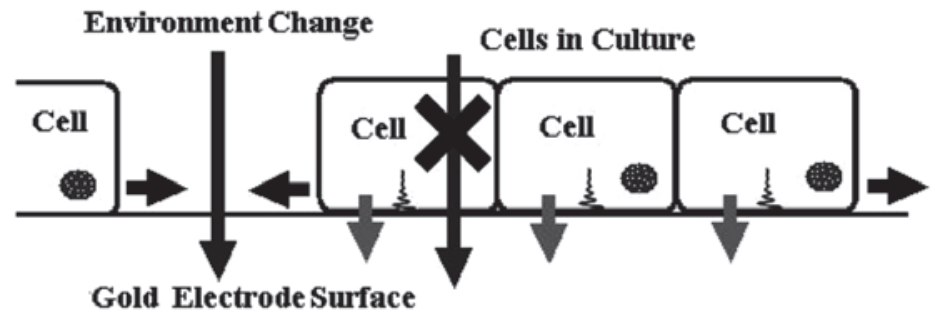

Fig. 11. Principle diagram of a QCM chip detecting Caco-2 cell tight junction permeability.

QCM crystal surface will also produce a frequency change. Talib et al. (2006) reported that different QCM solutions produce different signal frequencies. But there is only a constant distance at the electrode surface in which QCM can detect the change of solution. The QCM sensor in depth detection range decayed quickly at liquid because the QCM sensor shear wave was weakened in the solution. The QCM detection range from electrode surface up to the solution in the water is around $0.25 \mathrm{um}$, which represents only $1 / 10$ of the thickness of a cell (Nimeri et al., 1998). This is why QCM cannot detect environmental changes for the top layer of a cell. Based on the points in the previous paragraph, Fig. 11 shows that when the cell grows on the QCM surface, the electrode can only interact with cells that adhere to the surface. Therefore, QCM cannot detect solution changes beyond the cells. The more cells growing on the electrode surface, the smaller the surface of the electrode that is exposed to the solution. Therefore, when if we change the cell solution in samples where there is no impact to the physiology of cells, at least in the short-term, only the parts of the electrode surface without cell adhesion can be detected by changing of solution. The consequence is that the changing of QCM surface solution reduces the total frequency change. When the growing cells develop a completely tight junction membrane, 
replacing the solution produces only minimal frequency changes. The aforementioned concept described is the foundation used to test the completeness of the tight junction membrane in this study.

\subsubsection{Result}

In our study, we measured $\Delta \mathrm{f}$ changes every three days during cell cultivation. After testing, the chip was removed and analyzed for cell growth by a metallographic microscope. The population of cells (black dots or area) increased as the time elapsed on the surface of the sensor. There are a few black spots shown after $3 \mathrm{~d}$ (Fig. 12A); but grows into colonies in $9 \mathrm{~d}$ (Fig. 12B), and finally covers the entire sensor surface in $15 \mathrm{~d}$ (Fig. 12C). These facts prove that
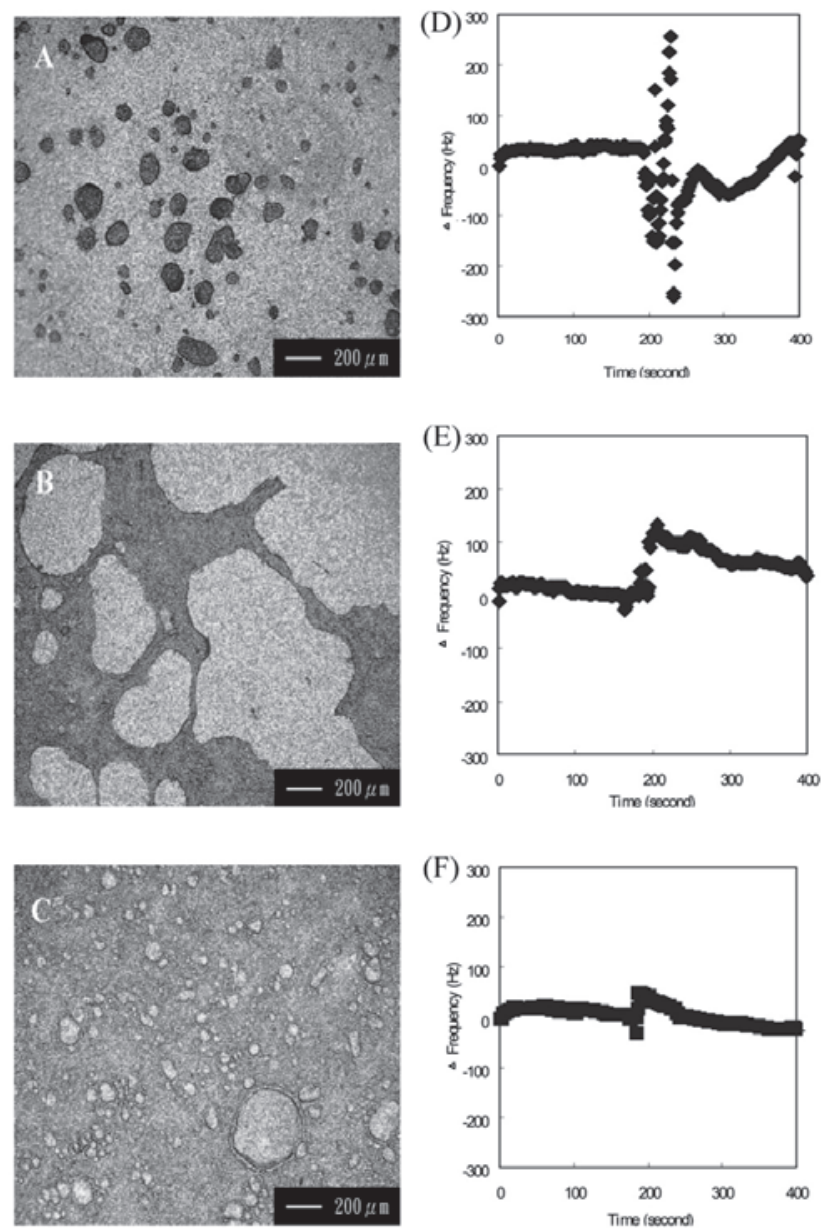

Fig. 12. Microscopic images of Caco-2 cell growth on the QCM cell sensor at (A) 3 days, (B) 9 days, $(C) 15$ days and measured frequency $(\Delta \mathrm{f})$ change of Caco-2 cell growth on the QCM cell sensor at (D) 3 days, (E) 9 days, (F) 15 days. 
cells can grow normally on the chip. The frequency profiles for cells cultured at 3, 9, and 15 $\mathrm{d}$ are shown in Fig. 12D, E, and F, respectively. The PBS was added to the chamber to allow the chip to react at $200 \mathrm{sec}$. As the cell growth quantity increased on the QCM surface, Df decreased when adding fixed quantities of PBS. Table 1 shows the amount of change for all reactions. These results demonstrate that the amount of reaction change for blank chips was about $258 \mathrm{~Hz}$. As cell growth continued, the amount of frequency change decreased. The changing amount of frequency was less than $100 \mathrm{~Hz}$ after $12 \mathrm{~d}$ of incubation. After incubating for over $15 \mathrm{~d}$, the amount of frequency change did not decrease further. Theoretically, when Caco- 2 cell forms a tight junction structure, close cell linkage reduces the degree of frequency change to zero. In addition to system noise, frequency did not reach zero due to possible physical shock and cell response of adding PBS. In addition, the quantity of frequency change was not stable at $0 \mathrm{~d}$. We consider that the chip was not stable at the beginning. Fig. 13 shows that cell growth increased over time while the frequency change and the TEER value decreased. The black line $(\Delta)$ represents the change of frequency results, and the gray line $(\circ)$ represents the control group TEER values. The result shows that the QCM and TEER detection system gave similar results with respect to cell over time, and that the QCM method successfully detected cell tight junction integrality.

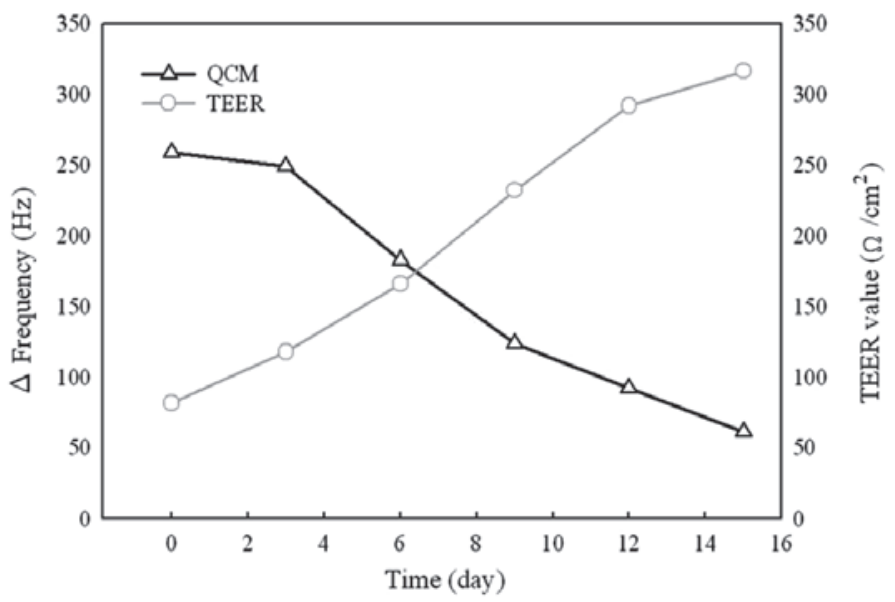

Fig. 13. Plot of cell tight junction integrality of frequency change measured by QCM and TEER vs.Caco-2 cells growth time. The black line $(\Delta)$ represents the change of frequency results in contrast to the gray line ( $\circ$ ) of TEER values.

\begin{tabular}{ccccccc}
\hline Cell growth (day) & 0 & 3 & 6 & 9 & 12 & 15 \\
\hline Exp. \#1 & 176 & 225 & 167 & 121 & 82 & 97 \\
$\Delta$ f (Hz) Exp. \#2 & 385 & 318 & 189 & 134 & 102 & 42 \\
Exp. \#3 & 215 & 204 & 192 & 116 & 92 & 45 \\
\hline Average & 258.7 & 249.0 & 182.7 & 123.7 & 92.0 & 61.3 \\
\hline S.D. & 111.1 & 60.7 & 13.7 & 9.3 & 10.0 & 30.9 \\
\hline
\end{tabular}

*S.D: standard deviation.

Table 1 . The frequency change $(\Delta f, H z)$ at different cell growth time (days) 


\subsection{Composite response of long-term cell monitoring from QCMs}

\subsubsection{Caco-2 cells adhesion state}

In the long-term monitoring of the Caco-2 cells growth on the surface of the fabricated QCM-cell system, the frequency decreased down rapidly during the period from 24 to 48 hours and then turned into a stable state. The situation was observed by Khraiche et al. (2005). There were similar results in our system (Fig. 14). All data revealed that cells attached and grown well on the surface of the QCM. The frequency turned into a stable state

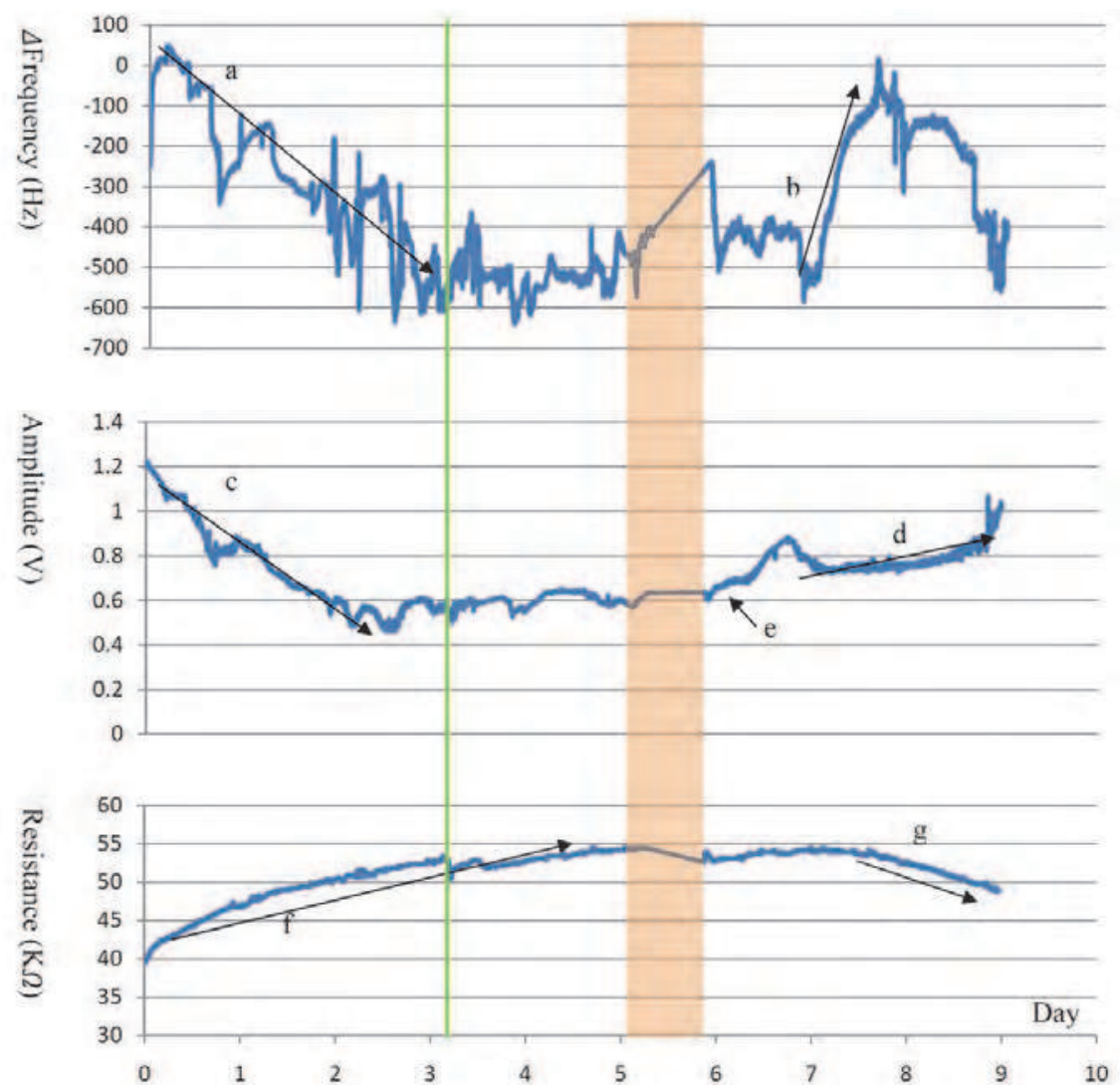

Fig. 14. Caco-2 cells growth condition was investigated using QCM.

after 3 days (arrow a: $\Delta \mathrm{f}=600 \mathrm{~Hz}$ ) and the amplitude showed the leading trend for about 1 day (arrow c: amplitude was from 1.2 to $0.5 \mathrm{~V}$ ). The TEER value continued to rise until the 5th day (arrow f: resistance was from 40 to $55 \mathrm{~K} \Omega$ ). The change of weight affecting the quartz resonant frequency and can be detected in the range for about $0.25 \mu \mathrm{m}$ above the quartz surface in a solution state (Talib et al., 2006). The affected depth was only one-tenth of cells in thickness, the change of frequency can be detected with the cells grown on the surface when cells attached on QCM, and the change of frequency cannot monitor the process of cell metabolism. The amplitude showed the leading trend possibly caused by the complex weight and ions 
effect, and the change of amplitude seemed to represent a response of QCM that was not more sensitive enough than the change of frequency. Nonetheless, we have a more interesting discussion about the change of amplitude which will be mentioned later. The TEER value does not continue to rise after the sixth day, which was likely caused by stopping the replacement of the medium. Thus, the TEER value reflected the integration degree of the cell membrane and the intact of tight junction which we could see from the rational curve.

\subsubsection{Caco-2 cells death process}

We found a dramatic change after stopping the replacement of medium. The frequency rose quickly to $600 \mathrm{~Hz}$ within 24 hours after the 7th day. However, the amplitude increased slowly (arrow d: amplitude was from 0.7 to $0.8 \mathrm{~V}$ ). The change of TEER value was lagged behind the change of frequency for about 12 hours (Fig. 14, arrow g: resistance was from 55 to $48 \mathrm{~K} \Omega$ ). The frequency response can be explicated by the reduced mass on the QCM surface. All means that the cells are in the process of death. We can propose the cells membrane rupture caused the TEER value decreased. We cannot explain the curve of the singular point. The sudden change in amplitude may be caused by changes in environmental change. The appearance may be a precursor of cell death.

\subsubsection{Caco-2 cells impedance analysis}

The impedance spectrum of a QCM sensor contains massive information in details that is particularly valuable in sensor applications (Sun, et al., 1996). Measurement of the change in the resonant frequency $(8.9 \sim 9.1 \mathrm{MHz})$ of the quartz crystal and the damping of its vibration can be extracted from the electrical impedance spectrum. Fig. 15 shows the sample of Caco-2 cells impedance analysis. From day 0 to day 5, we found the peak drop ping down because of the energy dissipation of QCM, the result was reasonable. The Caco-2 cells grew and attached on the surface of quartz, causing the energy loss of oscillation. From day 7 to day 9 , the dissipation was reduced implying the loading attached was reduced on the surface of QCM. This could possibly be explained as the evidence of the Caco-2 cells gradually dying.

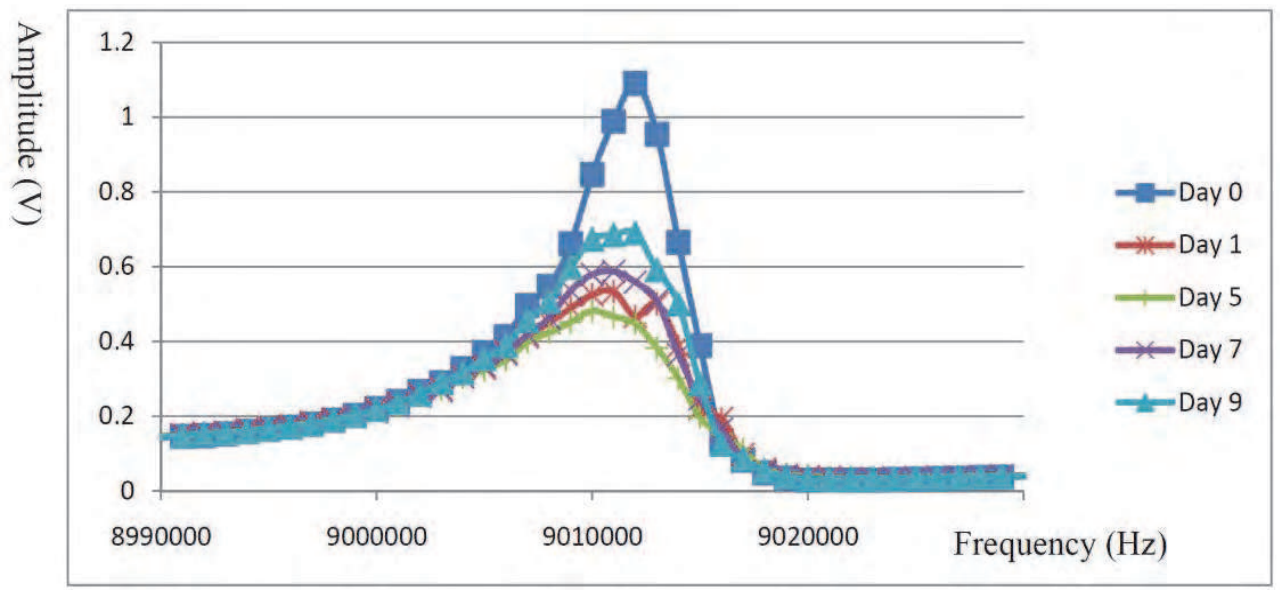

Fig. 15. Caco-2 cells impedance analysis. 


\subsubsection{Caco-2 cells treated with trypsin-EDTA}

One of our objectives was to design a cell-based QCM as a drug screening tool. Traditional biosensors are important and powerful tools in the drug discovery process. However, biosensors are limited to using a purified target molecule immobilized to the sensor surface. Cell-based QCM can simplify the process of biological mechanism in vivo situation. A Trypsin-EDTA $(0.05 \%$ Trypsin, $0.53 \mathrm{mM}$ EDTA-4Na) solution was used widely for dissociation of tissues and cell monolayer. Therefore, we used trypsin-EDTA as a poison and performed this simple test after cells grew on the QCM on day 6. There were three formulations as shown in the follows:

Formula 1: Trypsin-EDTA, $3 \mathrm{ml}$. (100\% v/v of Trypsin-EDTA)

Formula 2: Trypsin-EDTA, $2 \mathrm{ml}$. + DMEM, $1 \mathrm{ml}(66.7 \% \mathrm{v} / \mathrm{v}$ of Trypsin-EDTA)

Formula 3: Trypsin-EDTA, $1.5 \mathrm{ml}+$ DMEM, $1.5 \mathrm{ml}$ (50\% v/v of Trypsin-EDTA)

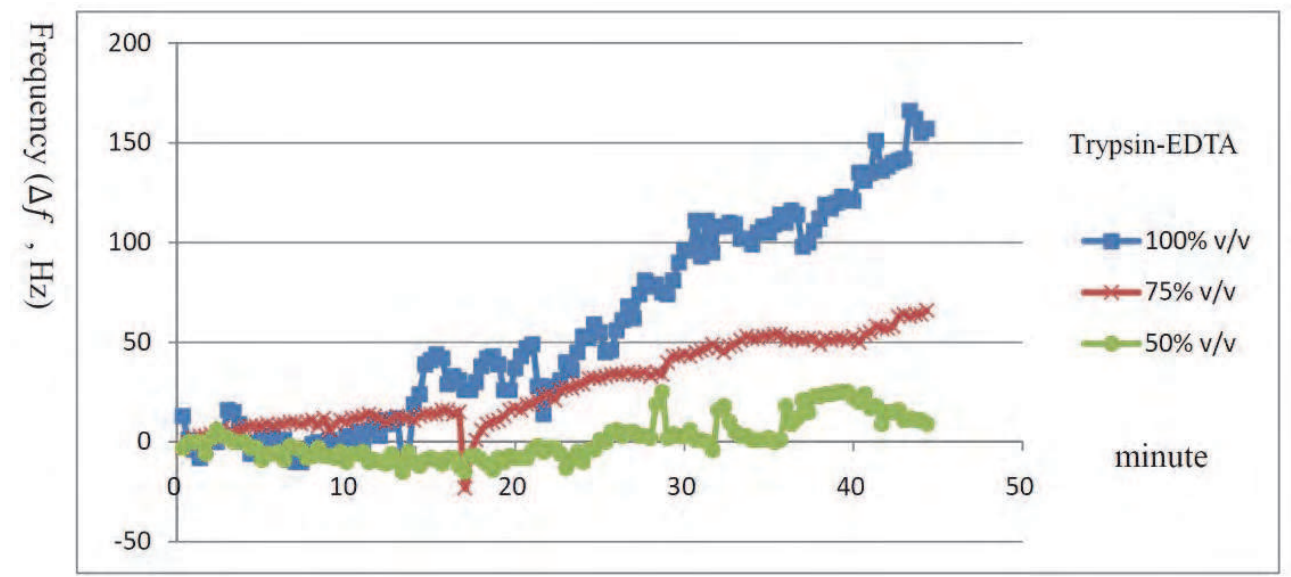

Fig. 16. Shows the change of frequency of QCM after the Caco-2 cells were treated with trypsin-EDTA.

After adding trypsin-EDTA, the Caco-2 cells began to detach from the golden-film of QCM, which made the frequency rapid increase as we predicted (Fig. 16). When Caco-2 cell medium was replaced by formula 1 , a maximum frequency increasing variation $(\Delta \mathrm{f} \cong 120 \mathrm{~Hz})$ took place and second one was shown in formula $2(\Delta \mathrm{f} \cong 120 \mathrm{~Hz})$ within the period of 40 minutes. We speculated the increase of frequency influenced by the weight loss of cells on the electrode surface. Of course, the density and viscosity decreasing also can influence the resonance of quartz. Formula 3 shows only a little impact exigency $(\Delta f \cong 25 \mathrm{~Hz})$, which could be neutralized by DMEM. Nonetheless, the similar result also appeared in the change of amplitude (Fig. 17). We can observed some difference change in $\Delta \mathrm{f}$ and $\Delta \mathrm{A}$. There exist a vigorously curve ( $\Delta \mathrm{A} \cong-0.2$ to $0.62 \mathrm{~V}$ ) at the beginning 20 minutes after application of formula 1. And there were similar upward trend lines after treated with formula 2 and 3. Formula 1, the Caco-2 cells were separated and isolated, causing cell-tight junction associated fracture. Formula $2 \& 3$, the Caco- 2 cells still remained intact cell tight junction. This may be 
the result of the complexity indifferent ion concentration and cells junction permeability as we expected. Table 2 shows the Caco- 2 cells survival testing by MTT assay ( $570 \mathrm{~nm}$ wavelength). We assume the Caco-2 cells survival rate is $100 \%$ which is to be treated with Formula 3 (OD: 1.172). Therefore the Caco-2 cells survival rate treated with formula 1 (OD: 0.889) and 2 (OD: 0.938 ) were $76 \%$ and $80 \%$. We believe these results were dissimilar to our experiment and we could not understand these Caco-2 cells likely to represent a good health condition or not. However we can illustrate the system by measuring amplitude and frequency of QCM which provide different biological detection in vivo.

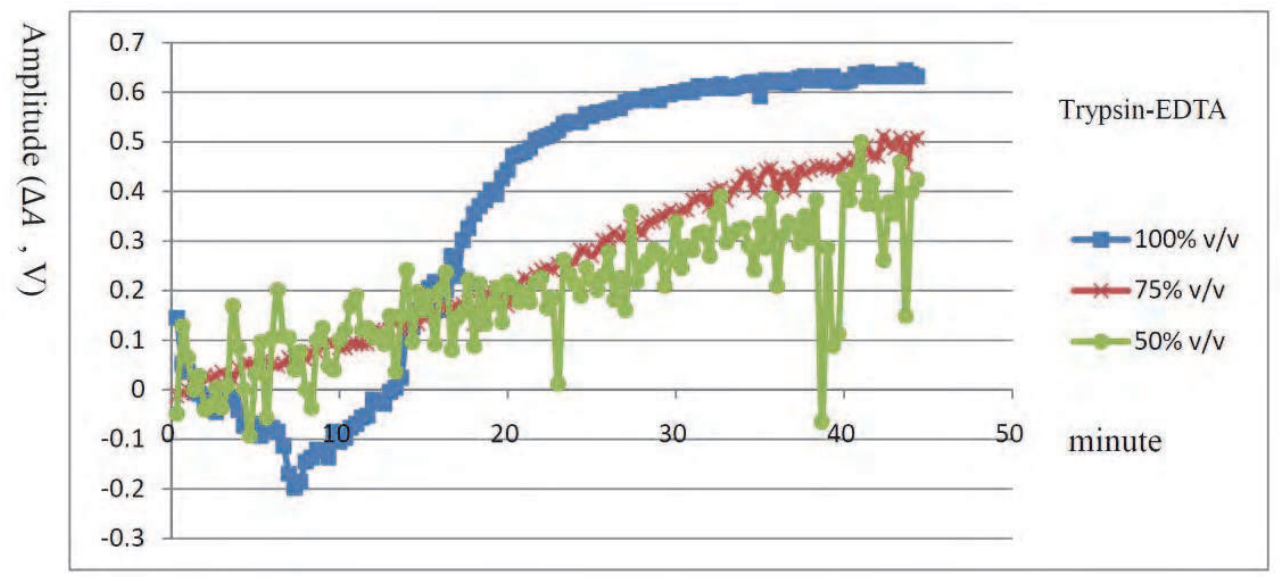

Fig. 17. Shows the change of amplitude of QCM after the Caco-2 cells were treated with trypsin-EDTA.

\begin{tabular}{c|ccccc}
\hline Trypsin-EDTA & 1 & 2 & 3 & Mean & Survive (\%) \\
\hline $100 \% \mathrm{v} / \mathrm{v}$ & 0.917 & 0.860 & 0.889 & $0.889 \pm 0.028$ & $76 \%$ \\
$66.7 \% \mathrm{v} / \mathrm{v}$ & 0.971 & 0.924 & 0.919 & $0.938 \pm 0.029$ & $80 \%$ \\
$50 \% \mathrm{v} / \mathrm{v}$ & 1.160 & 1.174 & 1.182 & $1.172 \pm 0.011$ & $100 \%$ \\
Blank & 0.133 & 0.128 & 0.125 & $0.129 \pm 0.004$ & --- \\
\hline
\end{tabular}

Table 2. Survival rate of the Caco-2 cells measured by MTT assay.

\section{Conclusion}

The QCM cell detection system was successfully designed in our laboratory. This system proves the model of Caco-2 cell growth. Using the HMDSZ of plasma-polymerized film and photo-induced polymerization of AAm is a feasible way to improve the hydrophilicity of silver electrodes. The proposed modification method involves binding a protective film. The longer the plasma-polymerized reaction time, the greater the film deposition and thickness have. An increased film thickness extends the film protection effect of sliver electrode, the HMDSZ film extends the unpeeling time of silver electrodes from 1 to 7 days. The cell growth experiments in the current study show no difference between amine groups or hydroxyl groups. However, the AAm-treated electrode offered better protection than the 
AAc-treated electrode. In summary, the experiment results of this study prove the feasibility of using a treated silver electrode QCM to detect cells.

During the process of cell growth and tight junction formation, this system detected frequency changes based on QCM reactions with different solutions. Results suggest that cells stay close together when the amount of frequency change is below $100 \mathrm{~Hz}$. The method is comparable to, but more versatile and convenient than, the TEER. The result showed that the QCM and TEER detection system gave similar results with respect to cells over time. This detection system makes it possible to detect the tight junction of Caco-2 cells and can be used for other cell detection in the future.

We developed a cell-based QCM measurement system for long-term monitoring cell growth in this study. This system provides an investigation of cell adhesion, proliferation, and death process. The cell growth conditions, medium composition and other factors will influence the QCM oscillation frequency, amplitude, and TEER value. To observe cell growth, prior studies showed that the crystal oscillation frequency can reflect the surface quality changes only for the cell membrane level. We investigate a trend of the changes in medium composition, cells metabolic, or intact of cell tight junction. The QCM resonance frequency and amplitude, the trans-epithelial electric resistance, and the electric impedance analysis, all illustrate the state of the cells in this study. Although these mechanisms are still uncertain, we believe that they could provide a method to develop a cell measurement technology for long-term observation of Caco-2 cell growth. This QCM-cell system opens QCM technology application fields and facilitates the researchers to follow-up screening and conducive for drugs development of related fields in vivo.

\section{Acknowledgements}

We gratefully acknowlede the finicial support of the National Science Council, Taiwan (NSC 98-2221-E-036-023-MY2 and NSC 100-2221-E-036-035).

\section{References}

Auge, J.; Hauptmanna, P.; Eichelbaumb, F. \& Rosler, S. (1994). Quartz crystal microbalance sensor in liquids, Sens. Actuators B: Chem., 18, pp. 518-522.

Bard, A.J. \& Faulkner, L.R. (2001). Electrochemical Method. Fundamentals and Applications, second ed. Wiley, New York, 2001. Biosens. Bioelectron, 23, 1259-68.

Bruckenstein, S. \& Shay, M. (1985). Experimental aspects of use of the quartz crystal microbalance in solution. Electrochim. Acta, 30, pp. 1295-1300

Buttry, D.A. \& Ward, M.D. (1992). Measurement of interfacial processes at electrode surfaces with the electrochemical quartz crystal microbalance. Chem. Rev., 92, pp. 1355-1379.

Braunhut, S.J.; McIntosh, D.; Vorotnikova, E.; Zhou, T. \& Marx, K.A. (2005). Detection of apoptosis and drug resistance of human breast cancer cells to taxane treatments using quartz crystal microbalance biosensor technology. Assay Drug Dev. Technol., 3, pp. 77-89

Cady, W.G. (1946). Piezoelectricity, McGraw-Hill, New York and London.

Chou, H.C.; Yan, T.R. \& Chen, K.S. (2009). Detecting cells on the surface of a silver electrode quartz crystal microbalance using plasma treatment. Colloids and Surfaces B: Biointerfaces, 73, pp.244-249 
Chou, H.C.; Yan, T.R., \& Lee, C.F. (2009). Matters needing attention for applying the quartz crystal microbalance technique to detect the cell morphology. BIOMED. ENG-APP. BAS. C., 21, pp. 415-420.

Chou, H.C.; Yan, T.R. (2010). Applying the quartz crystal microbalance technique to detect the epithelial cell tight junction integrality of Caco-2 cells. Anal. Lett., 43, pp. 2009 2018

Curie, P. \& Curie, J. (1880). Développement, par pression, de l'électricité polaire dans les cristaux hémièdres à faces inclines. Acad. Sci., 91, pp. 294-295.

Chen, K.S.; Chen, S.C.; Lin, H.R.; Yan T.R. \& Tseng, C.C. (2007). A novel technique to immobilize DNA on surface of a quartz crystal microbalance by plasma treatment and graft polymerization. Mater. Sci. Eng. C: Biomim. Supramol. Syst., 27, pp. 716.

Elsom, J.; Lethem, M.I.; Rees, G.D. \& Hunter A.C. (2008). Novel quartz crystal microbalance based biosensor for detection of oral epithelial cell-microparticle interaction in realtime, Biosens. Bioelectron., 23, pp. 1259.

Edvardsson, M.; Rodahl, M. \& Hook, F. (2006). Investigation of binding event perturbations caused by elevated QCM-D oscillation amplitude, Analyst., 131, pp. 822-828.

Eun, A.J.C.; Huang, L.; Chew, F.T.; Li, S.F.Y. \& Wong, S.M. (2002). Detection of two orchid viruses using quartz crystal microbalance (QCM) immunosensors. J. Virol. Methods, 99, pp. 71-79

Fawcett, N.C.; Evans J.A.; Chien, L.C. \& Flowers, N. (1988). Nucleic acid hybridization detected by piezoelectric resonance. Anal. Lett., 21, pp. 1099-1114

Fredriksson, C.; Khilman, S.; Kasemo, B. \& Steel, D.M. (1998a). In vitro real-time characterization of cell attachment and spreading. J. Mater. Sci.: Mater. Med., 9 (12), pp. 785-788.

Fredriksson, C.; Kihlman, S.; Rodahl, M. \& Kasemo, B. (1998b). The piezoelectric quartz crystal mass and dissipation sensor: a means of studying cell adhesion. Langmuir, 14, pp. 248-251.

Giaever, I. \& Keese, C.R. (1991). Micromotion of mammalian cells measured electrically. Proc. Natl. Acad. Sci. USA, 88, pp. 7896-7900.

Giaever, I. \& Keese, C.R. (1993). A morphological biosensor for mammalian cells. Nature, 366, pp. 591-592.

Gryte, D.M.; Ward, M.D. \& Hu, W.S. (1993). Real-time measurement of anchoragedependent cell adhesion using a quartz crystal microbalance. Biotechnol. Prog., 9, pp. $105-108$

Guilbault, G.G. (1983). Determination of formaldehyde with an enzyme coated piezoelectric crystal. Anal. Chem., 55, pp. 1682-1684.

Hao, R.Z.; Song, H.B \& Zuo, G.M. (2011). DNA probe functionalized QCM biosensor based on gold nanoparticle amplification for Bacillus anthracis detection. Biosens. Bioelectron., 26, pp. 3398-3404

Itamar, W.; Patolsky, F. Weizmann, Y. \& Willner, B. (2002). Amplified detection of singlebase mismatches in DNA using microgravimetric quartz-crystal-microbalance transduction. Talanta, 56, pp. 847-856.

Jenkins, M.; Horsfall, M.; Mathew, D.; Scanlon, M.; Jayasekara, R. \& Lonergan, G. T. (2004). Application of a quartz crystal microbalance to evaluate biodegradability of starch by Bacillus subtilis. Biotechnol. Lett., 26, pp. 1095-1099. 
Johannsmann D. (2008). "Viscoelastic, mechanical, and dielectric measurements on complex samples with the quartz crystal microbalance". Physical Chemistry, Chemical Physics, 10, pp. 4516-4534.

Kanazawa, K.K. \& Gordon, J.G. (1985). The oscillation frequency of a quartz resonator in contact with a liquid. Anal. Chim. Acta, 175, pp. 99-105

Khraiche,M.L.; Zhou, A. \& Muthuswamy, J. (2005). Acoustic sensor for monitoring adhesion of Neuro-2A cells in real-time, J. Neurosci. Methods, 144, pp. 1-10.

King, W.H. (1964). Piezoelectric sorption detector, Anal. Chem., 36, pp. 1735-1739.

Konash, P.L. \& Bastiaans, G.J. (1980). Piezoelectric crystals as detectors in liquid chromatography. Anal. Chem., 52, pp. 1929-1931

Lee, C.F; Yan, T. R. \& Chou, H.C. (2009). Improve the data acquisition system of a qcm sensor by increasing the sampling rate of frequency and amplitude. BIOMED. ENG-APP. BAS. C., 21 6, pp. 405-410

Lee, C.F.; Yan, T.R.; Chou, H.C. \& Lin, Z.Y. (2010). A quartz crystal microbalance cell-culture incubator system. 2010 INTERNATIONAL INNOVATION AND INVENTION CONFERENCE, pp.42 48, Taipei, Taiwan, September 26 27, 2010

Li, J.; Thielemann, C.; Reuning, U. \& Johannsmann, D. (2005). Monitoring of integrinmediated adhesion of human ovarian cancer cells to model protein surfaces by quartz crystal resonators: evaluation in the impedance analysis mode. Biosens Bioelectron., 20, pp. 1333-1340

Lippmann, G. (1881). Principe de conservation de l'électricité. Anal. Chim. Phys., 24, pp. 145-178.

Lu, C.S. \& Lewis, O. (1972). Investigation of film-thickness determination by oscillating quartz resonators with large mass load. J. Appl. Phys., 43, pp. 4385-4390.

Martin, S.J.; Granstaff, V.E.\& Frye, F.C. (1991). Characterization of a quartz crystal microbalance with simultaneous mass and liquid loading. Anal. Chem., 63, pp. 2272-2281.

Mirsky, V.M.; Riepl, M. \& Wolfbeis, O.S. (1997). Capacitive monitoring of protein immobilization and antigen-antibody reactions on monomolecular alkylthiol films on gold electrodes, Bios. Bioelec., 12, pp. 977-989.

Muramatsu, H.; Kijiwara K., Tamiya E., \& Karube I. (1986). Piezoelectric immuno sensor for the detection of Candida albicans microbes. Anal. Chim. Acta, 188, pp. 257-261

Muramatsu, H.; Tamiya, E. \& Karube I. (1988). Computation of equivalent circuit parameters of quartz crystals in contact with liquids and study of liquid properties, Anal. Chem., 60, pp. 2142-2146.

Muratsugu, M.; Romanschin, A.D. \& Thompson, M. (1997). Adhesion of human platelets to collagen detected by Cr51 labelling and acoustic wave sensor, Anal. Chim. Acta, 342, pp. 23-29.

Marx, K.A.; Zhou, T.; Warren M. \& Braunhut, S.J., (2003). Quartz crystal microbalance study of endothelial cell number dependent differences in initial adhesion and steadystate behavior: evidence for cell-cell cooperatively in initial adhesion and spreading. Biotechnol. Prog. 193, pp. 987-999.

Marx, K.A.; Zhou, T.; Montrone, A.; McIntosh, D. \& Braunhut, S.J. (2007). A comparative study of the cytoskeleton binding drugs nocodazole and taxol with a mammalian cell quartz crystal microbalance biosensor: Different dynamic responses and energy dissipation effects. Anal. Biochem., 361, pp. 77-92

Nimeri, G.; Fredriksson, C.; Elwing, H.; Liu, H.; Rodahl, M. \& Kasemo, B. (1998). Quartz crystal microbalance-based measurements of shear-induced senescence in human embryonic kidney cells. Surf. B: Biointerf., 11, pp. 225. 
Okahata, Y.; Kimura, K. \& Ariga, K. (1989). Detection of the phase transition of LangmuirBlodgett films on a quartz-crystal microbalance in an aqueous phase. J. Am. Chem. Soc., 111 26, pp. 9190-9194.

Park, I.S. \& Kim, N. (1998). Thiolated salmonella antibody immobilization onto the gold surface of piezoelectric quartz crystal. Biosens Bioelectron., 13, pp. 1091-1097

Pierce, G.W. (1923). Piezoelectric crystal resonators and crystal oscillators applied to the precision calibration of wavemeters. Proc. Am. Acad. Arts Sci., 59, pp. 81-106.

Redepenning, J.; Schlesinger T.K.; Mechalke E.J.; Puleo D.A. \& Bizios R. (1993). Osteoblast attachment monitored with a quartz crystal microbalance. Anal Chem., 65, pp. 3378-3381

Rodahl, M.; Hook, F.; Krozer, A.; Brzezinski, P. \& Kasemo, B. (1995). Quartz crystal microbalance setup for frequency and $\mathrm{Q}$-factor measurements in gaseous and liquid environments. Rev. Sci. Instr., 66, pp. 3924-3930.

Rodahl, M., B. Kasemo. (1996a). A simple setup to simultaneously measure the resonant frequency and the absolute dissipation factor of a quartz crystal microbalance. Rev Sci Instr, 67, pp. 3238-3241

Rodahl, M. \& Kasemo, B. (1996b). Frequency and Dissipation-factor response to localized liquid deposits on a QCM electrode. Sensors and Actuator B, 37, pp. 111-116.

Sauerbrey, G. (1959). The use of quartz oscillators for weighing thin layers and for microweighing. Z. Physik, 155, pp. 206-222.

Shumacher, R. (1990). The quartz crystal microbalance: a novel approach to the in situ investigation of interfacial phenomena at the solid/liquid junction, Angew. Chem. Int. Ed., 29, pp. 329-338.

$\mathrm{Su}$, X.L. \& Li, Y. (2004). An automatic quartz crystal microbalance immunosensor system for salmonella detection. ASAE Annual Meeting: 047043.

Sun, H.T.; Faccio, M.; Cantalini, C. \& Pelino, M. (1996). Impedance analysis and circuit simulation of quartz resonator in water at different temperatures. Sens. Actuators B, 32, pp. 169-173.

Tan, L.; Jia, X.; Jiang, X.F.; Zhang, Y.Y.; Tan, H.; Yao, S.Z. \& Xie, Q.G. (2008). Real-time monitoring of the cell agglutination process with a quartz crystal microbalance. Anal. Biochem., 383, pp. 130-136.

Talib, Z.A.; Baba, Z.; Kurosawa, S. \& Sidek, H.A.A. (2006). A. Kassimb and W.M.M. Yunus, Frequency behavior of a quartz crystal microbalance (QCM) in contact with selected solutions. Am. J. Appl. Sci., 3, pp. 1853-1858.

Ward, M.D. \& Buttery, D.A. (1990). In situ interfacial mass detection with piezoelectric transducers. Science 249, pp. 1000-1007.

Wegener, J.; Janshoff A. \& Galla, H.J. (1998). Cell adhesion monitoring using a quartz crystal microbalance: comparative analysis of different mammalian cells lines. Eur. Biophys. J., 28, pp. 26-37.

Wudy, F.; Multerer, M.; Stock, C.; Schmeer, G. \& Gores, H.J. (2008). Rapid impedance scanning QCM for electrochemical applications based on miniaturized hardware and high-performance curve fitting. Electrochim. Acta., 53, pp. 6568-6574.

Zhou, T.; Marx, K.A.; Warren, M.; Schulze, H. \& Braunhut, S.J. (2000). The quartz crystal microbalance as a continuous monitoring tool for the study of endothelial cell surface attachment and growth. Biotechnol. Prog., 16, pp. 268. 


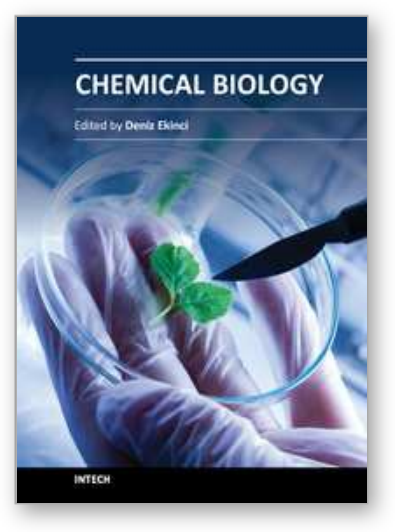

\author{
Chemical Biology \\ Edited by Prof. Deniz Ekinci
}

ISBN 978-953-51-0049-2

Hard cover, 444 pages

Publisher InTech

Published online 17, February, 2012

Published in print edition February, 2012

Chemical biology utilizes chemical principles to modulate systems to either investigate the underlying biology or create new function. Over recent years, chemical biology has received particular attention of many scientists in the life sciences from botany to medicine. This book contains an overview focusing on the research area of protein purification, enzymology, vitamins, antioxidants, biotransformation, gene delivery, signaling, regulation and organization. Particular emphasis is devoted to both theoretical and experimental aspects. The textbook is written by international scientists with expertise in synthetic chemistry, protein biochemistry, enzymology, molecular biology, drug discovery and genetics many of which are active chemical, biochemical and biomedical research. The textbook is expected to enhance the knowledge of scientists in the complexities of chemical and biological approaches and stimulate both professionals and students to dedicate part of their future research in understanding relevant mechanisms and applications of chemical biology.

\title{
How to reference
}

In order to correctly reference this scholarly work, feel free to copy and paste the following:

Tsong-Rong Yan, Chao-Fa Lee and Hung-Che Chou (2012). QCM as Cell-Based Biosensor, Chemical Biology, Prof. Deniz Ekinci (Ed.), ISBN: 978-953-51-0049-2, InTech, Available from:

http://www.intechopen.com/books/chemical-biology/qcm-as-cell-based-biosensor

\section{INTECH}

open science | open minds

\author{
InTech Europe \\ University Campus STeP Ri \\ Slavka Krautzeka 83/A \\ 51000 Rijeka, Croatia \\ Phone: +385 (51) 770447 \\ Fax: +385 (51) 686166 \\ www.intechopen.com
}

\author{
InTech China \\ Unit 405, Office Block, Hotel Equatorial Shanghai \\ No.65, Yan An Road (West), Shanghai, 200040, China \\ 中国上海市延安西路65号上海国际贵都大饭店办公楼405单元 \\ Phone: +86-21-62489820 \\ Fax: +86-21-62489821
}


(C) 2012 The Author(s). Licensee IntechOpen. This is an open access article distributed under the terms of the Creative Commons Attribution 3.0 License, which permits unrestricted use, distribution, and reproduction in any medium, provided the original work is properly cited. 